\title{
Electrochemical Anti-corrosion System of Iron Tower Based on Solar Power Supply
}

\author{
Tian Tian and Shiwu Xiao
}

${ }^{1}$ North China Electric Power University, School of Electrical and Electronic Engineering, 102206, Changping District, Beijing; China

\begin{abstract}
Aiming at the serious problem of the corrosion of the transmission tower in the coastal area or in the harsh industrial area, a kind of electro-chemical anti-corrosion system based on solar power is designed. The system consists of a solar power module and an electrochemical anti-corrosion module: The solar power module consists of a solar panel, a photovoltaic controller, a accumulator and a constant potentiometer. The Electrochemical anti-corrosion modules include an anode block and an anode bed and reference electrode. The photovoltaic energy technology and forced current cathodic protection technology are used in the system, to achieve the effective protection of the tower anti-corrosion. Solar power supply to the nearest, solve the long-distance transmission loss and the high installation costs, form a simple structure, stable operation, low cost, clean and environmental protection, long service life of anti-corrosion system, with good economic efficiency and social benefits. It is of great significance to ensure the safe operation of the tower, maintain the normal operation of the power grid, and even promotes the optimization and upgrading of the industrial structure, save energy and reduces emissions, improve the safe and stable operation of the power system and the economic benefits, etc.
\end{abstract}

\section{Introduction}

With the rapid development of China's power industry, and the full construction of a strong smart grid, transmission tower as bearing structure of high voltage transmission lines, it is particularly important to guarantee the safe and reliable operation. In recent years, the coastal new nuclear power plants, thermal power plants, power plants, substations growing, a large number of power plants to send lines through the coastal tidal flat, long-term open-air transmission tower, by sea water, sea breeze impact and corrosion. Most of the existing power transmission tower adopts steel structure in our country, in the general atmospheric environment, the existing transmission tower anti-corrosion measures can make its normal service for many years, basically meet the transmission tower operation requirements. However, in coastal areas or in harsh industrial areas, environmental factors such as the wet and salty meteorological factors and severe air pollution will significantly reduce the durability of the transmission tower. This will not only increase the maintenance workload of the relevant departments, waste steel resources, improve the cost, and there will be serious when may affect the normal operation of the transmission line, and reduces the reliability of the transmission system operation [1].

In the references 1 , the anti-corrosion of the transmission tower is analyzed in detail. At present, the anti-corrosion technology of the tower mainly includes hot-dip galvanizing, anticorrosive coating and external current cathodic protection. There are a lot of shortcomings in these technologies, mainly in: hot dip galvanized and anti-corrosion coating anti-iron tower corrosion method is not applicable to the coastal areas of humid and more salt environment, and in the construction, handling, welding and other processes easily lead to the damage, galvanized layer or paint layer loss of protection effect, and it will accelerate the corrosion of the tower, form pitting corrosion. In the references 2 , an anticorrosion device based on vibration-power generating of high-voltage transmission line is introduced. The anticorrosion device based on vibration-power generating of high-voltage transmission line is complicated and the installation is inconvenient. It is not conducive to the construction and maintenance. At the same time, the insulation cost of high-voltage transmission line vibration power device is high, poor efficiency. Therefore, to seek more effective tower anti-corrosion technology has become a matter of urgency [2].

A kind of electrochemical corrosion tower system based on solar power is introduced in this paper. the use of solar power technology and forced current cathodic protection technology to fundamentally contain the metal corrosion tendency and corrosion rate, thus effectively extending the life of the tower, reducing the relevant departments Maintenance of the workload, and the system of low cost, long life, in the conservation of steel resources, reduce the cost of investment effect is significant. Therefore, the economic benefits of the system are obvious.

At the same time, the system structure is simple, the operation is stable, it has no influence on the existing 
equipment, the existing structure needs no change, the installation is simple and convenient. In addition, the use of solar power to provide additional current, solve the problem of using traditional energy pollution, clean and environmental protection. Solar energy nearby power supply, avoids long-distance transmission loss, maintenance simple, suitable for unattended situation. The polarization current size can be adjusted, the tower electric potential can be artificially set, and automatic tracking control. Therefore, the design result also has important economic and social significance.

\section{Design principles and solutions}

The system mainly uses the technology of compulsory current cathodic protection, which provides cathodic dc current to the corroded tower metal materials, and protects the tower against corrosion. Cathodic protection is a method of polarizing a metal cathode to prevent it from being corroded. It is an electrochemical protection method. Use the principle of corrosion cell, the tower metal structure which need to be protected is as cathode. Through the anode to the cathode to provide electrons uninterrupted, the structure is polarization first, and then the electrons are enriched on the surface of the structure, making it difficult to produce ions, thus greatly slows down the structure of corrosion speed [3].

The design system consists of solar power supply module and electrochemical anti-corrosion module. Solar power module consists of solar panel, photovoltaic controller, accumulator and constant potentiometer, electrochemical anti-corrosion modules include anode block and anode bed and reference electrode. The system structure diagram is shown in Figure 1.

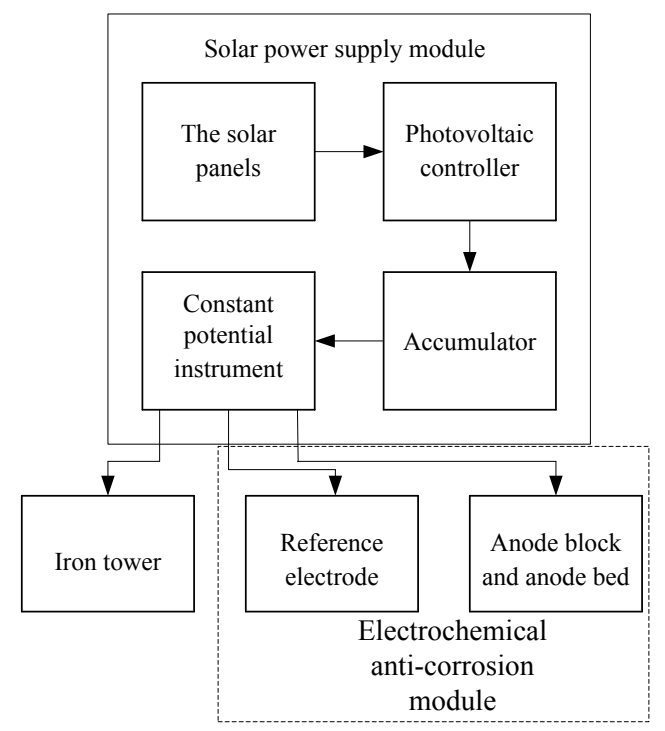

Figure 1. Block diagram of the anti-corrosion system.

The solar panel, photovoltaic controller, accumulators and potentiometer are connected in order. The output anode of the potentiostat is connected to the anode block and the anode bed with the wire, The output cathode of the potentiostat is connected to the lower part of the tower, The welding process is used to connect the wires directly to the internal steel so as to better protect the more easily corroded parts of the tower feet. The zero potential of the constant potentiometer is also connected to the cathode port of the tower lower part. The position of the connected power point is close to the output point of the output cathode of the potentiostat and the lower part of the tower, but it cannot be used to connect the zero to the output cathode with the short line. The sampling signal input terminal of the potentiometer is connected to the reference electrode.

The solar panel is installed on the tower, and the photovoltaic controller, battery and potentiometer are installed on the ground of the tower. The anode block and the anode bed are integrally formed and installed under the ground beneath the tower. The reference electrode is installed underground near the tower.

The protection process is as follows: the solar panel provides external power supply for the entire system, which converts solar energy into electricity in the light of sunlight. The role of PV controller is to control the working state of the solar power module, and to protect the battery through charging protection and overdischarge protection. The converted energy is stored in the battery by the PV controller and supplied to the potentiostat. Potentiostat give the tower a cathode current, and give the anode blocks and anode bed an anode current to constitute a corrosion cell, the reference electrode feedback is as constant standard, to control and adjust the polarization current output, and make the tower polarization within the scope of the protection potential, achieve the purpose of corrosion protection.

\section{Key module analysis and design}

\subsection{Design of electrochemical anti-corrosion module and power analysis}

The power analysis of electrochemical anti-corrosion was introduced in references 2, 3 and 4. Based on the analysis of the existing metal anti-corrosion methods, the system of electrochemical anti-corrosion of iron tower based on solar power generation is proposed in this paper. The electrochemical anti-corrosion module includes anode block and anode bed and reference electrode.

\subsubsection{Anode block and anode bed}

When choosing anodic material, it is necessary to take a comprehensive consideration of its characteristics, which generally requires good conductivity of anode materials, strong corrosion resistance, long life, large discharge, and sufficient mechanical strength.

The commonly used anode materials are graphite, stainless steel, high silicon iron, magnetic iron oxide, lead silver (2\%) alloy and platinum-plated titanium tube (rods), etc.. These materials have good corrosion resistance characteristics. In this paper theoretical analysis, graphite is used as the anode block, but it is not limited to this in actual production, If necessary, it can also use waste steel, aluminum, zinc and other materials. Fill the anode block 
with coke as material and form an anode bed. The setting of coke anode bed can significantly reduce the actual consumption rate of anode materials, thus extending the service life of anode blocks $[2,3,4]$.

\subsubsection{Reference electrode}

Commonly used reference electrode materials are $\mathrm{Ag} / \mathrm{AgCl}$ electrode, $\mathrm{Cu} / \mathrm{CuSo} 4$ electrode and $\mathrm{Zn}$ electrode. Here the reference electrode used $\mathrm{Ag} / \mathrm{AgCl}$ electrode.

\subsubsection{Power analysis of electrochemical anticorrosion of iron towers.}

Access to the relevant provisions of the country, the bottom pillar of the tower can be simplified as a cylinder [2,3,4]: diameter $d=0.1 \mathrm{~m}$, length $L=4 \mathrm{~m}$, concrete diameter $D=0.5 \mathrm{~m}$. Surface area of tower feet: $S=\pi d L=0.4 \pi$, Select tower protection current density $[2,3,4]: \quad i=10 \mathrm{~mA} / \mathrm{m}^{2}$, Single tower pillar current: $I=i S=12.5 \mathrm{~mA} \quad, \quad$ Total circuit current: $I_{\text {total }}=4 I=50 \mathrm{~mA} \quad, \quad$ Required anode mass: $G=T g I / K=0.4 \mathrm{Kg}, \quad$ Required anode block volume: $V=G / \rho=95.8 \mathrm{~cm}^{3}$.

Where $T$ is the design life of the electrode $30 \mathrm{a}, g$ for the electrode consumption rate $0.158 \mathrm{~kg} / \mathrm{A} . \mathrm{a}, K$ for the electrode effective utilization coefficient $0.5, I$ for the electrode operating current $0.1 \mathrm{~A}$.

In the design, the graphite body is taken as the anode block: diameter $d_{\text {graphite }}=4 \mathrm{~cm}$, length $L_{\text {graphite }}=25 \mathrm{~cm}$, take coke as anode bed: buried depth $t=1.9 \mathrm{~m}$, diameter $d_{\text {coke }}=20 \mathrm{~cm}$, length $L_{\text {coke }}=60 \mathrm{~cm}$. Access to information [5]:

Soil resistivity: $\rho_{\text {soil }}=200 \Omega \cdot \mathrm{m}$, Coke resistivity: $\rho_{\text {coke }}=50 \Omega \cdot \mathrm{m}$, Concrete resistivity, $\rho_{\text {concrete }}=300 \Omega \cdot \mathrm{m}$, Contact resistance of graphite to coke:

$$
\begin{gathered}
R_{1}=\frac{0.0171 \rho_{\text {coke }}}{L_{\text {graphite }}} \times \ln \left(\frac{8 L_{\text {graphite }}}{d_{\text {graphite }}}-1\right) \\
=\frac{0.0171 \times 50}{0.25} \times \ln \left(\frac{8 \times 25}{4}-1\right)=13.31 \Omega
\end{gathered}
$$

Contact resistance of coke and soil [6] :

$$
\begin{gathered}
R_{2}=\frac{\rho_{\text {soil }}}{2 \pi L_{\text {coke }}} \times \ln \frac{2 L_{\text {coke }}}{d_{\text {coke }}} \times \sqrt{\frac{4 t+3 L_{\text {coke }}}{4 t+L_{\text {coke }}}} \\
=\frac{200}{2 \pi \times 0.6} \times \ln \frac{2 \times 0.6}{0.2} \times \sqrt{\frac{4 \times 1.9+3 \times 0.6}{4 \times 1.9+0.6}} \\
=101.77 \Omega
\end{gathered}
$$

Anode potential

$$
U_{1}=I_{\text {total }}\left(R_{1}+R_{2}\right)
$$

$$
=0.05 \times(13.31+101.77)=5.754 \mathrm{~V}
$$

Contact resistance of tower and concrete:

$$
\begin{gathered}
R_{3}=\frac{\rho_{\text {concrete }}}{2 \pi L_{\text {tower }}} \times \ln \left(\frac{4 L_{\text {tower }}}{d_{\text {tower }}}-1\right) \\
=\frac{300}{2 \pi \times 4} \times \ln \left(\frac{4 \times 4}{0.1}-1\right)=60.506 \Omega
\end{gathered}
$$

Contact resistance of concrete and soil:

$$
\begin{aligned}
R_{4} & =\frac{\rho_{\text {soil }}}{2 \pi L_{\text {tower }}} \times \ln \frac{4 L_{\text {tower }}}{D_{\text {concrete }}}=27.3268 \Omega \\
& =\frac{200}{2 \pi \times 4} \times \ln \left(\frac{4 \times 4}{0.5}-1\right)=27.3268 \Omega
\end{aligned}
$$

Cathode potential:

$$
\begin{gathered}
U_{2}=-I\left(R_{3}+R_{4}\right) \\
=-0.0125 \times(60.506+27.3268)=-1.098 \mathrm{~V}
\end{gathered}
$$

Power of electrochemical anticorrosive consumption:

$$
P=I_{\text {total }}\left(U_{1}-U_{2}\right)=0.05 \times(5.745+1.098)=0.343
$$

\subsection{Power supply module design and power analysis}

The solar power module consists of a solar panel, a photovoltaic controller, a battery and a potentiostatic instrument.

\subsubsection{Solar panels}

The solar panel is the core of the module, providing an additional power source for the entire system, which converts solar energy into electricity in the light of sunlight.

Firstly, the power of solar panel is analyzed. The process is as follows:

According to the equation (7), the power of electrochemical anticorrosive consumption is $0.34 \mathrm{~W}$, and the system protects the tower continuously throughout the day. Therefore, the electricity consumption every day is: $0.343 \times 24=8.23 \mathrm{WH}$. Considering the loss in the circuit and the storage process, the power supply efficiency is 0.7 , and the effective sunshine time of the day is equal to 5h. The output power of the solar panel should be:

$$
P=8.23 / \eta / 5=2.35 \mathrm{~W}
$$

In design system, 12V/3W solar panels are selected.

\subsubsection{Photovoltaic controller}

PV controller main technical indicators:

1) Rated voltage: $12 \mathrm{~V}$,

2) Rated current: $30 \mathrm{~A}$, 
3 ) Overload, short circuit protection: 1.25 times rated current 30 seconds, 1.5 times rated current 5 seconds, overload protection action, 3 times rated current short circuit protection.

\subsubsection{Accumulator}

Battery selection voltage is $12 \mathrm{~V}$, calculating battery capacity: $8.23 \mathrm{WH} / 12 \mathrm{~V}=0.68 \mathrm{AH}$, That is, the daily power consumption is $12 \mathrm{~V} / 0.68 \mathrm{AH}$.

The design requires that the system can work normally during the continuous rain for 3 days. The battery daily power consumption should be controlled within $30 \%$, thus requiring a $12 \mathrm{~V} / 2 \mathrm{AH}$ battery.

\subsubsection{The potentiostat.}

Main technical parameters of the potentiometer:

1) potential control range: $\pm 2 \mathrm{~V}$, continuous adjustment,

2) Constant potential characteristics: $\pm 0.1 \%(\mathrm{~F}, \mathrm{~S})$,

3) Stability: $\pm 0.5 \%$ (F,S) $/ 24$ hours

\section{Corrosion process of the forced current cathodic protection}

\subsection{Theoretical analysis}

In the case of forced current cathodic protection: there is an oxidation reaction on the boundary of the anode block (graphite, zinc block, scrap steel, etc.) and the hydrogen evolution reaction occurring on the protected cathode [7].

\subsection{Model building}

\subsubsection{Model structure}

To facilitate the modeling process and the ease of data selection, select zinc as the anode block, and the model structure is shown in Figure 2.

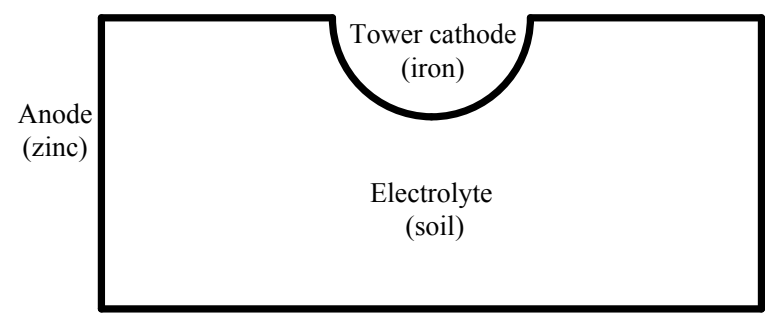

Figure 2. Model diagram of forced current cathodic protection.

\subsubsection{Electrochemical current modeling}

Use secondary current distribution interface for electrochemical current modeling, the diffusion of oxygen in the soil is described by the thin matter transfer interface. The oxidation and diffusion coefficient depends on the pore saturation of the pores.

\subsubsection{Boundary conditions}

The potential of the zinc anode is selected as the ground potential. Assuming that the reaction kinetics of the zinc anode is very fast, the polarization can be neglected, so the electrolyte potential is set as:

$$
\phi_{1, Z n}=-E_{e q, Z n}+\phi_{s, Z n}=-E_{e q, Z n}
$$

where $E_{e q, Z n}$ is the empirical measurement of the equilibrium potential of zinc/earth electrode. In the model, $E_{e q, Z n}$ is set to $-0.68 \mathrm{~V}$. The oxygen concentration on the anode of $\mathrm{Zn}$ is set to the concentration in the atmosphere:

$$
C_{O_{2}, Z n}=C_{O_{2}, r e f}
$$

Three different electrode reactions need to be considered on the boundary of the tower and soil, namely the oxidation of iron, the reduction of oxygen and the hydrogen dissociation reaction. The reaction equation is as follows:

$$
\left\{\begin{array}{l}
\mathrm{Fe} \rightarrow \mathrm{Fe}^{2+}+2 e^{-} \\
\mathrm{O}_{2}+2 \mathrm{H}_{2} \mathrm{O}+4 e^{-} \rightarrow 4 \mathrm{OH}^{-} \\
2 \mathrm{H}_{2} \mathrm{O}+2 e^{-} \rightarrow \mathrm{H}_{2}+4 \mathrm{OH}^{-}
\end{array}\right.
$$

The kinetics of these reactions are modeled through the electrode surface nodes in the secondary current distribution interface. In this boundary condition, the external electrical potential of the rebar $\phi_{s, \text { steel }}$ is set as the applied battery potential $-1 \mathrm{~V}$.

The electrode dynamics of rebar reaction are described according to the Tafel expression:

$$
\left\{\begin{array}{l}
i_{\mathrm{Fe}}=i_{0, \mathrm{Fe}} \times 10^{A_{\mathrm{Fe}} \eta_{\mathrm{Fe}}} \\
i_{\mathrm{O}_{2}}=-\frac{c_{\mathrm{O}_{2}}}{c_{\mathrm{O}_{2}, \mathrm{ref}}} i_{0, \mathrm{O}_{2}} \times 10^{A_{\mathrm{O}_{2}} \eta_{\mathrm{O}_{2}}} \\
i_{\mathrm{H}_{2}}=-i_{0, \mathrm{H}_{2}} \times 10^{A_{\mathrm{H}_{2}} \eta_{\mathrm{H}_{2}}}
\end{array}\right.
$$

In modeling, some parameters of reference are shown in Table 1, and the potential of each reaction is calculated according to equation (13).

$$
\eta=\phi_{s, s t e l}-\phi_{l}-E_{e q}
$$

Table 1. Main parameters of simulation.

\begin{tabular}{|c|c|c|c|c|}
\hline parameter & unit & $\mathrm{Fe}$ & $\mathrm{O}_{2}$ & $\mathrm{H}_{2}$ \\
\hline $\begin{array}{c}\text { Balance potential, } \\
\text { Eeq }\end{array}$ & $\mathrm{V}$ & -0.76 & 0.189 & -1.03 \\
\hline $\begin{array}{c}\text { Exchange current } \\
\text { density, } i o\end{array}$ & $\mathrm{~A} / \mathrm{m}^{2}$ & $7.1 \times 10^{-5}$ & $7.7 \times 10^{-7}$ & $1.1 \times 10^{-2}$ \\
\hline Tafel Slope, $A$ & $\begin{array}{c}\mathrm{V} / \\
\text { decade }\end{array}$ & 0.41 & -0.18 & -0.15 \\
\hline
\end{tabular}

According to Faraday's law, the oxygen reduction reaction on the steel surface produces an oxygen flux, which can be modeled using the electrode electrolyte interface coupling node in the lean transfer interface. The 
other boundaries use symmetrical boundary conditions, and the initial values of the oxygen concentration are atmospheric.

\section{Conclusion}

This paper designs an electrochemical anti-corrosion system based on solar power. In view of the defects of the existing steel tower anti-corrosion technology, the power of electrochemical anti-corrosion protection of the tower was carried out by using the compulsory current cathodic protection technology, and solar power was used as the system energy. The anti-corrosion system based on solar power supply fundamentally curbs the corrosion tendency and corrosion rate of the metal, thus effectively prolong the life of the tower, reducing the maintenance workload of the related departments, and the system of low cost, long service life, to save steel resources, reduce the investment cost effect is remarkable. In addition, the system structure is simple, the operation is stable, it has no influence on the existing equipment, the existing structure needs no change, and installation is simple and convenient. The use of solar power to provide additional current has solved the problem of the use of traditional energy pollution. Solar energy nearby power supply, avoids long-distance transmission loss, maintenance simple, suitable for unattended situation. The polarization current size can be adjusted, the tower potential can be artificially set, and automatic tracking control. These features make the design of the tower of electrochemical corrosion protection system based on solar power has a good economic and social benefits, can be applied to the actual production, with a certain practical value.

\section{References}

1. Chengzhi Ma, Hongcang Yang, Qiyu Yu, Weizheng Liang, Yueling Lin. Comparison and Analysis on Anticorrosion Methods of Transmission Tower in Coastal Area[J]. Electromechanical engineering technology, 2014(12).141-144,218.

2. Ming Ge, Jinda Mao, Chen Zhang, Yiping Shang, Jiachen Bian, Yueming Liu,Wenbin Wu. A Design of Electrochemical Protection for the Tower Based on Vibration-Power Generating of Lines[J]. Transmission and Distribution Engineering and Technology, 2014(3).69-75

3. Xu Bai. The Application Study and the technology of Anti - corrosion of Substation Grounding Grid Based on Cathodic Protection Principle[D]. Master's thesis, North China Electric Power University, 2011.

4. Yunjin Yang. The simplified calculation of conductor shockproof[J]. Design of coal mine. 1980(3).18-20,40

5. Fengping Wang, Wanli Kang, Hemin Jing. Principles, methods and applications of corrosion electrochemistry [M]. 2008.

6. [6] Jianhong Wang, Quan Tang Anti-corrosion coating technology of concrete structure of Shantou Bay Bridge[J]. China New Technologies and New Products,2010(9).49

7. http:// cdn.comsol.com/ documentation/ 5.2.1.262 / COMSOL_Software License Agreement. zh_CN. Pdf 